\title{
Real Estate Portfolio Size and Risk Reduction
}

\author{
A Paper Presented at the Annual \\ European Real Estate Society (ERES) Meeting \\ Dublin, Ireland \\ June 2005 \\ Steven Devaney \\ Investment Property Databank Limited \\ 7-8 Greenland Place \\ London, NW1 OAP England
}

Phone: +44 (0)20 7643 9268; fax: 44 (0)20 7267 0208; e-mail: Steven.Devaney@ipdindex.co.uk

Stephen Lee

The University of Reading Business School,

Centre for Real Estate Research (CRER),

The University of Reading,

Reading, RG6 6AW

England

Phone: +44 (0)118378 6338; Fax: +44 118378 8172; e-mail: S.L.Lee@reading.ac.uk

\begin{abstract}
The reduction of portfolio risk is important to all investors but is particularly important to real estate investors as most property portfolios are generally small. As a consequence, portfolios are vulnerable to a significant risk of under-performing the market, or a target rate of return and so investors may be exposing themselves to greater risk than necessary. Given the potentially higher risk of underperformance from owning only a few properties, we follow the approach of Vassal (2001) and examine the benefits of holding more properties in a real estate portfolio. Using Monte Carlo simulation and the returns from 1,728 properties in the IPD database, held over the 10-year period from 1995 to 2004, the results show that increases in portfolio size offers the possibility of a more stable and less volatile return pattern over time, i.e. down-side risk is diminished with increasing portfolio size. Nonetheless, increasing portfolio size has the disadvantage of restricting the probability of out-performing the benchmark index by a significant amount. In other words, although increasing portfolio size reduces the down-side risk in a portfolio, it also decreases its up-side potential. Be that as it may, the results provide further evidence that portfolios with large numbers of properties are always preferable to portfolios of a smaller size.
\end{abstract}

Keywords: Real Estate, Size and Risk Reduction 


\section{Real Estate Portfolio Size and Risk Reduction}

\section{Introduction}

Studies in the financial literature demonstrate, on an empirical basis, that naive diversification results in the reduction of portfolio risk. For instance, Evans and Archer (1968) show that the connection between increasing portfolio size and portfolio risk takes the form of a rapidly decreasing asymptotic function. The authors refuted the notion that there is any economic justification for a portfolio that includes more than 10 securities; results supported by the later work of Fisher and Lorie (1970) and Elton and Gruber (1977). They show that there is a reduction in diversifiable risk of between $84 \%$ and $88 \%$ if the stock portfolio size is increased by only eight stocks. However, both studies find that there are further diversification effects if the portfolio size is increased by more than eight stocks. Similar results have also been suggested for the real estate market; see inter alia, Jones Lang Wootton (1986), Brown (1988, 1991) and Brown and Matysiak (2001).

These conclusions are usually arrived at by plotting the standard deviation (or variance) of portfolio returns against the number of assets in a portfolio. This plot is generally shown to be a "smooth" asymptotic curve, meant to present the basic message of reduction of unsystematic risk (and thus total risk) through diversification and demonstrate the impact of the number of holdings in a portfolio on its risk. However, fund managers are typically evaluated by comparing their return performance to that of a specified benchmark. A successful manager, therefore, is one who can outperform the benchmark. Consequently the risk faced by a fund manager is the risk of underperformance not the volatility of returns of the portfolio per se. In the real estate market this view of risk is particular important as real estate portfolios tend to concentrate their holdings in relatively few properties, due to the large lot sizes and illiquidity in the market. For instance, the median number of properties held by a sample of 136 institutional investors in the UK was only 45 over the 11-years from 1989-1999 (Byrne and Lee, 2003). As a consequence, real estate fund managers are vulnerable to significant risk of under-performing the market or a target rate of return and so may be exposing the fund and themselves to greater risk than necessary.

Vassal (2001) takes this view of risk and, using the total returns of stocks from the Russell 1000 index over the seven-year period from 1992 to 1999, examines the frequency of under-performing a number of benchmarks, such as the market return and the rate of inflation, by simulating a large number of naive (equally-weighted) portfolios. Vassal (2001) makes no certain recommendations about the optimal portfolio size, but he determines a portfolio size of up to 100 securities to be useful to reduce the risk of underperformance.

This study uses the approach of Vassal (2001) and investigates the benefits of holding more properties in a real estate portfolio so as to minimise the probability of underperformance relative to a market benchmark. The analysis uses Monte Carlo techniques to simulate total returns of real estate portfolios with varying numbers of properties for the 10-year period from 1995 to 2004. The results suggest that adding only 
a few properties to a real estate portfolio produces substantial reductions in portfolio risk but at the cost of limiting the potential of achieving superior returns.

The remainder of the paper is organised as follows. The next section discusses the data used. Section 3 outlines the methodology and presents the results. Section 4 concludes the paper and suggests future areas of research.

\section{Data}

To analyse the risk of portfolios with different numbers of holdings, we use data on properties in the Investment Property Databank (IPD) UK database. One limitation with this dataset is that performance of individual properties is not traced through different ownerships. This means that the data are essentially all property investments that were held within portfolios and not traded, or subject to re-development during the period. Even with this restriction, there are still annual total returns (capital appreciation plus income) for up to 1,728 properties over the period 1995 to $2004^{1}$. These assets show a certain amount of survivor bias, in the order of $0.9 \%$ per annum, when compared to the performance of the databank as a whole. Summary statistics for the dataset and the index are presented in Table 1.

Table 1 shows that the median return of a typical property from the sample in any one year is about $12 \%$. However, in some years the range of individual returns can be as much as $306 \%$ (1997), while the inter-quartile range is only about $10 \%$ on average. In other words, in any one year some properties perform exceptionally well or very badly but the majority cluster around the median.

The 10-year cumulative total return of the individual properties was then calculated we create a frequency distribution with the total return results, the results shown in Figure 1. Figure 1 shows the percentage of individual properties with a cumulative total return within a specific range. Only one of the sampled properties would have shown a negative return over this 10 -year period. However, $45 \%$ of the individual properties achieved less than $200 \%$ over the 10 -year period, while the IPD index would have almost doubled in value over the same period (188\%). Meanwhile, if an investor had randomly bought only one property at the end of 1995 , there was about a $40 \%$ chance that the investment would have under-performed the market benchmark. This example highlights the potential risk of investing in only one property.

\section{Methodology and Results}

We use Monte Carlo simulation techniques to randomly select multiple combinations of individual properties from the dataset as of year-end 1994. The process of simulation was done by randomly selecting properties to create a portfolio of size $\mathrm{N}$ by using drawings from a rectangular distribution with values between 1 and 1,728, each drawing referring to an individual property. The returns of the selected properties in each year were then averaged together to create an equal-weighted portfolio return for each year.

\footnotetext{
${ }^{1}$ All the analysis was performed at IPD to protect investor confidentiality.
} 
These portfolio returns were then compounded to produce a 10-year cumulative return. This procedure was conducted ten thousand times for each value of $\mathrm{N}$ to create a large number of equal-weighted property portfolios, ranging in size from 2 to 100 properties.

After generating the multiple property portfolios, we create frequency distributions with the total return results. The frequency distributions in Table 2 present the percentage of simulated portfolios (with the same number of properties) with returns within a specific range.

Table 2 shows that $61 \%$ of the simulated five-property portfolios had a cumulative total return between $200 \%$ and $300 \%$ for the 10-year period ending 2004, while, more than $98 \%$ of the 50-property portfolios reflected cumulative total returns between the same ranges. The analysis supports the hypothesis that the dispersion of portfolio returns is inversely related to the number of properties in a portfolio and supports the results of numerous studies in the equity and real estate markets.

\subsection{Downside Risk}

As suggested above, the risk faced by managers of real estate portfolios is typically that of under-performing a benchmark index. We therefore analysed the downside risk faced by managers holding different sized portfolios. In order to do this, we first examined the frequency of under-performing the market, as measured by the IPD UK Annual Index (IPD, 2005), for the portfolios of different sizes. However, to tackle the presence of survivor bias in the sample, a second comparison was made with the sample median as the benchmark return.

The left half of Table 3 shows the frequency of under-performing the sample median. In this example, we take the average (median) return (212\%) for all properties in the sample as a market benchmark for the historical 10-year period. As shown in Table 3, the probability of substantial under-performance is dramatically reduced for portfolios with more properties. About one in three of the simulated 10-property portfolios reflect total returns below the benchmark return. The probability of under-performing the sample median is less than one in seventeen for 75-property portfolios.

The left half of Table 4 then displays the comparison of performance of the different size portfolios against the IPD Index. Table 4 shows that compared with the cumulative total return of the IPD Index over the 10-year period, the probability of underperformance by the sampled properties was always less than that of under-performing the sample median. For instance, the 10-property portfolio size has only a one in ten chance of achieving returns of less than the IPD index compared with a one in three chance when analysed against the sample median. The probability of under-performing the IPD Index falls to a negligible one in a hundred at portfolio size 30 and to zero for portfolio of 75 properties or more.

The greater decline in probability of underperformance when using the IPD index as the benchmark as opposed to the sample median reflects the use of standing investments in 
the simulations, i.e. properties that were neither bought nor sold over this period. The data in Table 1 showed that such properties have shown good performance over this period and so were retained by investors whereas poor performing properties are more likely to have been sold and so leave the database, but whose returns are included in the overall market index at some stage.

\subsection{Up-side potential}

The results so far show that increasing portfolio size significantly reduces the risk of under-performing a benchmark index. Indeed, Figures 1 and Table 2 both suggest that the probability of out-performing the benchmark index is always greater than underperformance from holding greater numbers of properties within the portfolio, i.e. the sample data and simulated portfolios are positively skewed. This results from the fact that the maximum loss faced by any property investment is $-100 \%$, but the maximum gain is limitless. For instance, Figure 1 shows that one in five of the individual properties achieved cumulative total returns in excess of $350 \%$ over this 10-year period. Accordingly, the likelihood of getting one of these super performers in the simulations is amplified with increased portfolio size. This is an encouraging result for fund managers, as it suggests that the risk of failure is not only diminished but that the likelihood of beating the benchmark index is increased with greater portfolio size.

It is clear from the right halves of Tables 3 and 4 that the probability of out-performing the benchmark index (sample median or IPD index), however, by more than say 50\% over this 10 -year period is severely curtailed with increasing portfolio size. For instance, while there is a one in four chance of achieving returns in excess of the sample median by more than $50 \%$ for portfolios of five-properties, the chances of significantly outperforming by more than $50 \%$ diminishes to less than one in fifty for portfolios of size 75 and to almost zero for portfolio of size 100 .

The comparable figures when comparing the sample against the IPD index are again much better at 38\%, 35\%, 29\% and 25\% for portfolios with, 10-, 30-, 75- and 100properties respectively, results that again need to be moderated by the selection bias that probably exists in the sample data.

This finding confirms the results of Cullen (1991) who used IPD data from 1981 to 1990 and found that while larger portfolios seem to ensure against the downside risk of low returns they also preclude high performance levels. In other words, larger portfolios are able to track the market index more closely than smaller portfolios, but at the cost of limits on the probability of significant superior performance, while smaller portfolios are generally unable to provide the fund manager with the ability to track the market with any degree of certainty, but offer a much broader range of return performance.

\section{Conclusion}

The investigation of risk reduction from increasing portfolio size is particularly important to real estate investors, as most property portfolios are generally very small. As a result, 
investors and fund managers face a high chance of under-performing a benchmark index. Using Monte Carlo simulation and the returns from 1,728 properties in the IPD database over the 10-year period from 1995 to 2004, the results show that increases in portfolio size offer the possibility of a more stable and less volatile return pattern over time, i.e. down-side risk is diminished with increasing portfolio size. Nonetheless, increasing portfolio size has the disadvantage of restricting the probability of out-performing the benchmark index by a significant amount. In other words, although increasing portfolio size reduces the down-side risk in a portfolio, it also decreases its up-side potential. Be that as it may, the results provide further evidence that portfolios with large numbers of properties are always preferable to portfolios of a smaller size.

However, any analysis is subject to caveats and this research is no exception. For instance, the study so far is based upon randomly selecting properties and therefore precludes the impact that stock selection may have on performance. Additionally, the analysis is based on constructing equal-weighted portfolios, which is both impractical and probably undesirable in the real estate market. Consequently, natural extensions of this analytical approach should try to incorporate other factors into the analysis to further reduce downside risk, while enhancing up-side potential. Examples are sector constraints and beta limits in the formation of the portfolios. These and other issues are being actively pursued by the authors at the present time. 


\section{References}

Brown, G.R. (1988) Reducing the Dispersion of Returns in UK Real Estate Portfolios, Journal of Valuation, 6, 2, 127-147.

Brown, G.R. (1991) Property Investment and the Capital Markets, E. \& F.N. Spon, London.

Brown, G.R. and Matysiak, G.A. (2001) Real Estate Investment: A Capital Market Approach, Financial Times Prentice Hall, London

Byrne, P. and Lee, S.L. (2003) An Exploration of the Relationship between Size, Diversification and Risk in UK Real Estate portfolio: 1989-1999, Journal of Property Research, 20, 2, 191-206

Cullen, I. (1991) Risk Management in Investment Property Portfolios, Presented as part of the seminar series organised by the Society of Property Researchers and the RICS, entitled Property in a Portfolio Context.

Elton, E.J. and Gruber, M.J. (1977) Risk Reduction and Portfolio Size: An Analytical Solution, Journal of Business, 50, 415-437.

Evans, J.L. and Archer, S.H. (1968) Diversification and the Reduction of Dispersion: An Empirical Analysis, Journal of Finance, 23, 761-767.

Fisher, L. and Lorie, J.H. (1970) Some Studies of Variability of Returns on Investments in Common Stocks, Journal of Business, 43, 2, April, 99-134

IPD (2005) IPD UK Annual Index, Investment Property Databank, London

Jones Lang Wootton (1986) Risk and Asset Allocation: Implications of Portfolio Strategy.

Vassal, V. de (2001) Risk Diversification Benefits of Multiple Stock Portfolios: Holding between One and One hundred stocks, Journal of Portfolio Management, 27, 2, 32-39. 
Table 1: Summary Statistics of Sample and Index Data

\begin{tabular}{lcccccccccc}
\hline Year & 1995 & 1996 & 1997 & 1998 & 1999 & 2000 & 2001 & 2002 & 2003 & 2004 \\
\hline Max return in yr & 204.1 & 87.4 & 244.1 & 100.1 & 74.9 & 112.6 & 97.0 & 135.8 & 112.4 & 204.4 \\
75th percentile & 9.1 & 13.9 & 22.1 & 17.2 & 19.6 & 16.1 & 12.7 & 17.4 & 19.5 & 25.7 \\
Median & 4.7 & 9.8 & 15.0 & 10.9 & 13.8 & 9.8 & 8.3 & 11.9 & 13.0 & 19.5 \\
25th percentile & -0.8 & 6.3 & 9.7 & 6.3 & 8.8 & 4.3 & 3.2 & 7.7 & 7.9 & 13.8 \\
Min return in yr & -32.1 & -34.7 & -62.1 & -32.9 & -45.1 & -85.2 & -34.7 & -30.3 & -40.7 & -48.4 \\
\hline Sample v Index & 1995 & 1996 & 1997 & 1998 & 1999 & 2000 & 2001 & 2002 & 2003 & 2004 \\
\hline Sample No. of Properties & 1728 & 1728 & 1728 & 1728 & 1728 & 1728 & 1728 & 1728 & 1728 & 1728 \\
Index No. of Properties & 15841 & 15482 & 15368 & 15385 & 14483 & 14311 & 12472 & 11865 & 11038 & 10986 \\
Sample Av. Return & 4.2 & 11.0 & 17.4 & 11.6 & 15.2 & 11.7 & 8.1 & 10.9 & 12.0 & 19.6 \\
Index Av. Return & 3.6 & 10.0 & 16.8 & 11.8 & 14.5 & 10.5 & 6.8 & 9.6 & 10.9 & 18.3 \\
\hline
\end{tabular}


Figure 1: The Frequency Distribution of Individual Cumulative Property Returns 1995 to 2004

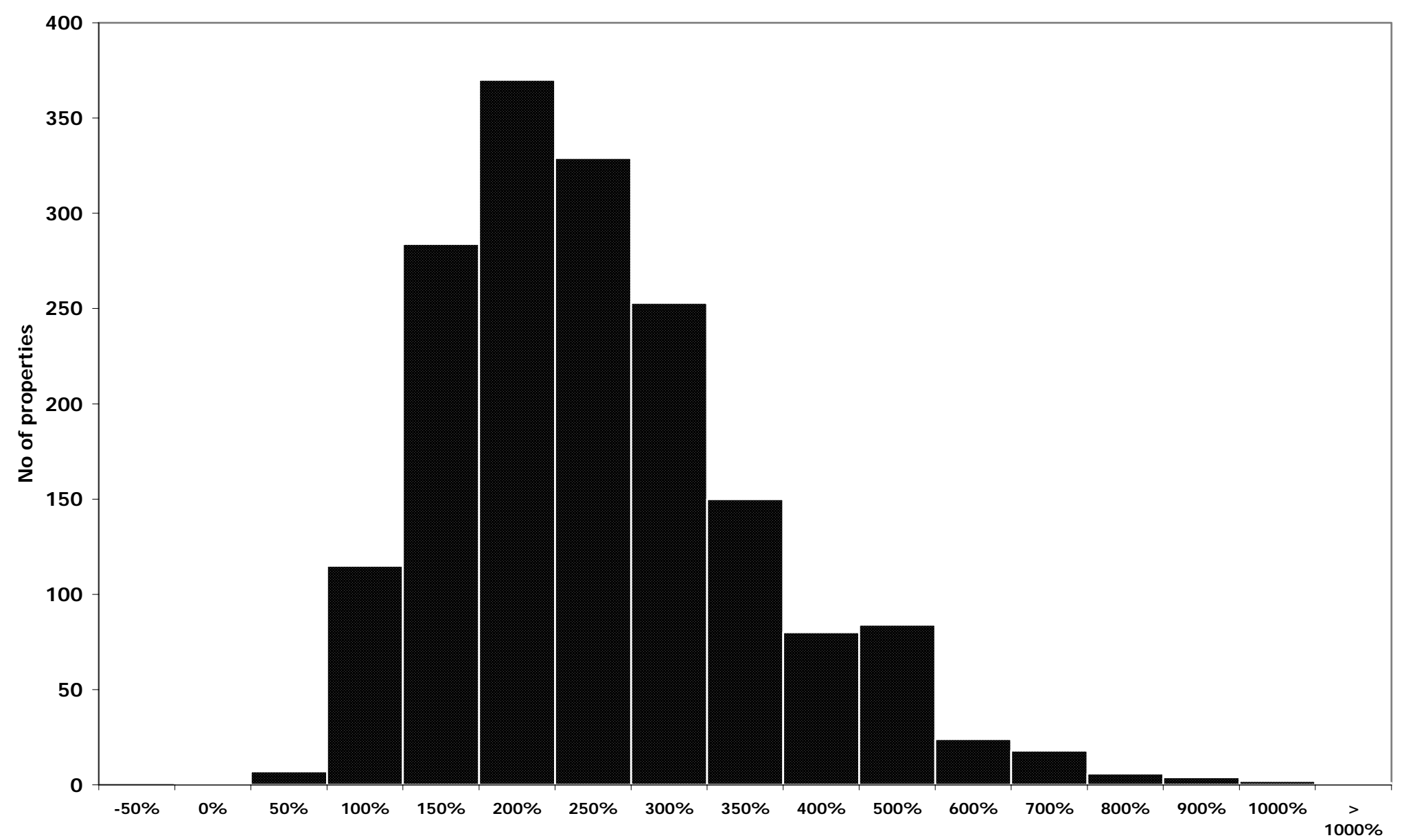

Page 8 
Table 2: Frequency Distribution of Cumulative Property Returns 1995-2004 for Different Portfolio Sizes: 10,000 Simulations

\begin{tabular}{|c|c|c|c|c|c|c|c|c|c|c|c|c|c|c|c|c|c|c|c|}
\hline & 1 & 2 & 3 & 4 & 5 & 6 & 7 & 8 & 9 & 10 & 12 & 15 & 20 & 25 & 30 & 40 & 50 & 75 & 100 \\
\hline-100 to $0 \%$ & $0.1 \%$ & & & & & & & & & & & & & & & & & & \\
\hline 0 to $25 \%$ & $0.2 \%$ & & & & & & & & & & & & & & & & & & \\
\hline 25 to $50 \%$ & $0.2 \%$ & & & & & & & & & & & & & & & & & & \\
\hline 50 to $75 \%$ & $2.5 \%$ & $0.3 \%$ & & & & & & & & & & & & & & & & & \\
\hline 75 to $100 \%$ & $4.2 \%$ & $1.3 \%$ & $0.3 \%$ & $0.1 \%$ & & & & & & & & & & & & & & & \\
\hline 100 to $125 \%$ & $6.8 \%$ & $3.9 \%$ & $1.8 \%$ & $0.8 \%$ & $0.4 \%$ & $0.2 \%$ & $0.1 \%$ & & & & & & & & & & & & \\
\hline 125 to $150 \%$ & $10.2 \%$ & $8.1 \%$ & $6.1 \%$ & $4.1 \%$ & $2.8 \%$ & $1.7 \%$ & $1.1 \%$ & $0.8 \%$ & $0.6 \%$ & $0.3 \%$ & $0.1 \%$ & & & & & & & & \\
\hline 150 to $175 \%$ & $11.6 \%$ & $11.8 \%$ & $11.3 \%$ & $10.2 \%$ & $8.7 \%$ & $7.8 \%$ & $6.6 \%$ & $5.3 \%$ & $4.8 \%$ & $4.0 \%$ & $2.7 \%$ & $1.6 \%$ & $0.6 \%$ & $0.3 \%$ & $0.1 \%$ & & & & \\
\hline 175 to $200 \%$ & $9.5 \%$ & $14.1 \%$ & $15.0 \%$ & $16.9 \%$ & $17.0 \%$ & $17.0 \%$ & $17.0 \%$ & $16.6 \%$ & $16.0 \%$ & $15.8 \%$ & $14.3 \%$ & $12.8 \%$ & $8.9 \%$ & $7.1 \%$ & $5.1 \%$ & $3.2 \%$ & $1.8 \%$ & $0.4 \%$ & $0.1 \%$ \\
\hline 200 to $225 \%$ & $10.6 \%$ & $14.1 \%$ & $17.3 \%$ & $18.8 \%$ & $21.5 \%$ & $22.5 \%$ & $24.1 \%$ & $25.4 \%$ & $26.1 \%$ & $26.7 \%$ & $29.2 \%$ & $30.4 \%$ & $32.0 \%$ & $32.4 \%$ & $33.8 \%$ & $34.2 \%$ & $33.8 \%$ & $31.3 \%$ & $28.2 \%$ \\
\hline 225 to $250 \%$ & $9.0 \%$ & $12.6 \%$ & $15.1 \%$ & $16.9 \%$ & $18.1 \%$ & $20.3 \%$ & $21.3 \%$ & $22.5 \%$ & $24.4 \%$ & $25.6 \%$ & $27.3 \%$ & $30.2 \%$ & $35.5 \%$ & $39.0 \%$ & $41.7 \%$ & $46.6 \%$ & $50.9 \%$ & $59.7 \%$ & $65.6 \%$ \\
\hline 250 to $275 \%$ & $7.1 \%$ & $9.9 \%$ & $11.5 \%$ & $12.5 \%$ & $13.6 \%$ & $13.9 \%$ & $14.5 \%$ & $15.3 \%$ & $15.0 \%$ & $15.5 \%$ & $16.4 \%$ & $16.9 \%$ & $17.2 \%$ & $16.7 \%$ & $16.4 \%$ & $14.6 \%$ & $12.7 \%$ & $8.5 \%$ & $6.1 \%$ \\
\hline 275 to $300 \%$ & $6.8 \%$ & $7.2 \%$ & $7.5 \%$ & $7.9 \%$ & $7.9 \%$ & $8.1 \%$ & $8.1 \%$ & $7.7 \%$ & $8.0 \%$ & $7.8 \%$ & $6.7 \%$ & $6.1 \%$ & $4.8 \%$ & $3.8 \%$ & $2.6 \%$ & $1.4 \%$ & $0.8 \%$ & $0.2 \%$ & \\
\hline 300 to $325 \%$ & $5.0 \%$ & $5.2 \%$ & $5.1 \%$ & $5.1 \%$ & $4.6 \%$ & $4.4 \%$ & $4.3 \%$ & $3.9 \%$ & $3.2 \%$ & $2.8 \%$ & $2.3 \%$ & $1.7 \%$ & $1.0 \%$ & $0.7 \%$ & $0.3 \%$ & $0.1 \%$ & & & \\
\hline 325 to $350 \%$ & $3.8 \%$ & $3.5 \%$ & $3.3 \%$ & $2.9 \%$ & $2.4 \%$ & $2.4 \%$ & $1.7 \%$ & $1.4 \%$ & $1.3 \%$ & $1.2 \%$ & $0.7 \%$ & $0.3 \%$ & $0.2 \%$ & & & & & & \\
\hline 350 to $375 \%$ & $2.4 \%$ & $2.4 \%$ & $2.2 \%$ & $1.6 \%$ & $1.6 \%$ & $0.8 \%$ & $0.8 \%$ & $0.7 \%$ & $0.5 \%$ & $0.3 \%$ & $0.1 \%$ & $0.1 \%$ & & & & & & & \\
\hline 375 to $400 \%$ & $2.4 \%$ & $1.7 \%$ & $1.3 \%$ & $1.0 \%$ & $0.7 \%$ & $0.6 \%$ & $0.4 \%$ & $0.3 \%$ & $0.1 \%$ & $0.1 \%$ & $0.1 \%$ & & & & & & & & \\
\hline 400 to $425 \%$ & $1.2 \%$ & $1.1 \%$ & $0.9 \%$ & $0.5 \%$ & $0.4 \%$ & $0.3 \%$ & $0.1 \%$ & $0.1 \%$ & & & & & & & & & & & \\
\hline 425 to $450 \%$ & $1.4 \%$ & $0.8 \%$ & $0.5 \%$ & $0.3 \%$ & $0.2 \%$ & $0.1 \%$ & & & & & & & & & & & & & \\
\hline 450 to $475 \%$ & $1.1 \%$ & $0.7 \%$ & $0.3 \%$ & $0.2 \%$ & $0.1 \%$ & & & & & & & & & & & & & & \\
\hline 475 to $500 \%$ & $1.0 \%$ & $0.4 \%$ & $0.2 \%$ & $0.1 \%$ & $0.1 \%$ & & & & & & & & & & & & & & \\
\hline 500 to $525 \%$ & $0.2 \%$ & $0.3 \%$ & $0.1 \%$ & & & & & & & & & & & & & & & & \\
\hline 525 to $550 \%$ & $0.4 \%$ & $0.2 \%$ & $0.1 \%$ & & & & & & & & & & & & & & & & \\
\hline 550 to $575 \%$ & $0.5 \%$ & $0.1 \%$ & $0.1 \%$ & $0.1 \%$ & & & & & & & & & & & & & & & \\
\hline 575 to $600 \%$ & $0.3 \%$ & $0.1 \%$ & & & & & & & & & & & & & & & & & \\
\hline $601 \%+$ & $1.8 \%$ & $0.3 \%$ & $0.1 \%$ & & & & & & & & & & & & & & & & \\
\hline
\end{tabular}


Table 3: Frequency of Downside Risk and Upside Potential Compared with Sample Median for Portfolios of Differing Sizes: 10,000 Simulations

\begin{tabular}{cccc|ccc}
\hline Portfolio & \multicolumn{2}{c|}{ Frequency of Under-performance } & \multicolumn{3}{c}{ Frequency of Out-performance } \\
\cline { 2 - 7 } Size & $<-50 \%$ & -50 to $-25 \%$ & -25 to $0 \%$ & 0 to $25 \%$ & 25 to $50 \%$ & $50 \%+$ \\
\hline 1 & 29.8 & 10.7 & 10.1 & 10.2 & 7.4 & 31.8 \\
2 & 18.4 & 13.6 & 14.0 & 13.9 & 11.0 & 29.1 \\
3 & 12.8 & 13.6 & 16.3 & 16.6 & 13.9 & 26.8 \\
4 & 9.0 & 13.3 & 18.9 & 18.6 & 14.9 & 25.4 \\
5 & 6.2 & 12.8 & 20.1 & 20.6 & 15.9 & 24.4 \\
10 & 1.4 & 8.5 & 22.3 & 27.8 & 21.3 & 18.8 \\
15 & 0.2 & 5.2 & 22.1 & 32.5 & 24.8 & 15.1 \\
20 & 0.1 & 2.6 & 18.9 & 38.0 & 27.9 & 12.6 \\
25 & - & 1.7 & 17.4 & 41.3 & 28.6 & 11.0 \\
30 & - & 0.9 & 16.0 & 44.8 & 29.6 & 8.7 \\
50 & - & 0.1 & 10.8 & 53.5 & 31.8 & 3.9 \\
75 & - & - & 5.6 & 60.3 & 32.6 & 1.5 \\
100 & - & - & 3.4 & 65.1 & 31.1 & 0.5 \\
\hline
\end{tabular}

Table 4: Frequency of Downside Risk and Upside Potential Compared with IPD Index for Portfolios of Differing Sizes: 10,000 Simulations

\begin{tabular}{cccc|ccc}
\hline Portfolio & \multicolumn{2}{c|}{ Frequency of Under-performance } & \multicolumn{3}{c}{ Frequency of Out-performance } \\
\cline { 2 - 7 } Size & $<-50 \%$ & -50 to $-25 \%$ & -25 to $0 \%$ & 0 to $25 \%$ & 25 to $50 \%$ & $50 \%+$ \\
\hline 1 & 19.9 & 10.9 & 10.5 & 9.8 & 10.4 & 38.5 \\
2 & 9.2 & 10.6 & 13.5 & 14.0 & 13.9 & 38.9 \\
3 & 4.7 & 9.0 & 13.9 & 16.6 & 16.6 & 39.2 \\
4 & 2.6 & 7.3 & 13.8 & 19.2 & 18.2 & 39.0 \\
5 & 1.4 & 5.4 & 13.6 & 20.5 & 20.3 & 38.8 \\
10 & 0.1 & 1.6 & 9.5 & 23.3 & 27.5 & 38.1 \\
15 & - & 0.3 & 6.2 & 23.5 & 32.5 & 37.5 \\
20 & - & 0.1 & 3.2 & 20.7 & 38.5 & 37.5 \\
25 & - & - & 2.3 & 20.1 & 41.3 & 36.3 \\
30 & - & - & 1.3 & 18.6 & 45.2 & 34.9 \\
50 & - & - & 0.2 & 13.5 & 55.2 & 31.2 \\
75 & - & - & - & 8.1 & 63.1 & 28.7 \\
100 & - & - & - & 5.1 & 69.5 & 25.4 \\
\hline
\end{tabular}

